\title{
PSIKOEDUKASI MENGENAI DAMPAK BULLYING DAN CARA MENINGKATKAN SELF-ESTEEM PADA REMAJA
}

\author{
Grace Amin ${ }^{1}$ \\ ${ }^{1}$ Universitas Presiden \\ Email: grace_amin@president.ac.id
}

\begin{abstract}
Bullying is deliberate aggressive action, using an imbalance of strength physically or mentally by hurting physical, verbal, or emotional / psychological forms repeatedly. In the last decade, cases of bullying in Indonesia continue to increase and if not handled properly will increasingly have a negative impact on the development of the children of the nation's next generation. Bullying does not only affect children who are bullied but can also affect children who bully, children who witness bullying. Some of the effects of bullying include anxiety, depression, and low self-esteem. The purpose of community engagement is to socialize the impact of bullying and how to increase self-esteem to adolescents. Through psychoeducation programs in adolescents such as schools and teenagers religious communities in the Cikarang - Bekasi region, young people gain an in-depth understanding of bullying, its effects and how to increase their confidence. Through this psychoeducation, teenagers understand the understanding, types and effects of bullying both short term and long term so they promise to resist bullying starting from themselves. Teenagers learn that humans are social beings who need each other. They learn about the meaning of diversity and bhineka tunggal $i k a$ and try to implement it in their next lives by respecting the differences in their environment. These teenagers learn to respect themselves more, see the positive things that God has given them. They try to always believe in themselves that they are perfect and valuable beings in God's eyes so that even though the environment around them may not appreciate, they can still see positive things in themselves.
\end{abstract}

Keywords: Psychoeducation; bullying; self-esteem; a teenager.

\begin{abstract}
ABSTRAK
Bullying adalah tindakan agresif yang disengaja, menggunakan ketidakseimbangan kekuatan secara fisik atau mental dengan cara menyakiti bentuk fisik, verbal, atau emosional/ psikologis secara berulang - ulang. Dalam satu decade terakhir, kasus bullying di Indonesia terus meningkat dan bila tidak ditangani dengan baik akan semakin berdampak negative bagi perkembangan anak - anak generasi penerus bangsa. Tindakan bullying tidak hanya berdampak pada anak yang di-bully tetapi juga dapat berdampak pada anak yang mem-bully, anak yang menyaksikan bullying. Beberapa dampak bullying diantaranya kecemasan, depresi, serta rendahnya harga diri (self-esteem). Tujuan dari pengabdian kepada masyarakat ini adalah untuk mensosialisasikan dampak bullying serta cara meningkatkan selfesteem kepada para remaja. Melalui program psikoedukasi di lingkungan remaja seperti sekolah maupun komunitas keagamaan remaja wilayah Cikarang - Bekasi, para remaja mendapatkan pemahaman mendalam mengenai bullying, dampaknya serta bagaimana cara meningkatkan kepercayaan diri mereka. Melalui psikoedukasi ini, para remaja memahami pengertian, jenis serta dampak bullying baik jangka pendek maupun jangka panjang sehingga mereka berjanji untuk bersikap menolak bullying mulai dari diri mereka sendiri. Para remaja belajar bahwa manusia adalah mahluk social yang saling membutuhkan. Mereka belajar tentang makna keberagaman dan Bhineka Tunggal Ika serta berusaha mengimplementasikannya dalam kehidupan mereka selanjutnya dengan cara menghargai perbedaan yang ada di lingkungannya. Remaja ini belajar untuk lebih menghargai diri mereka, melihat hal positif yang telah diberikan Tuhan kepada mereka. Mereka mencoba untuk selalu menanamkan dalam diri bahwa mereka adalah mahluk yang sempurna dan berharga di mata Tuhan sehingga walaupun lingkungan di sekitar mereka mungkin tidak menghargai, mereka tetap dapat melihat hal positif dalam diri mereka.
\end{abstract}

Kata kunci: Psikoedukasi; bullying; self-esteem; remaja. 


\section{PENDAHULUAN}

Bullying adalah kekerasan fisik dan psikologis jangka panjang yang dilakukan seseorang atau kelompok terhadap seseorang yang tidak mampu mempertahankan dirinya. Ada beberapa jenis atau tipe bullying yaitu verbal bullying, social bullying, physical bullying. Bullying merupakan salah satu issue kesehatan kompleks yang berdampak tidak hanya pada usia anak dan remaja namun pada semua usia. (Rattew \& Pawlowski, 2015).

Berdasarkan informasi Komisioner Komisi Perlindungan Anak Indonesia (KPAI) Jasa Putra, sejak 2011 hingga 2016 telah terjadi 23 ribu kasus kekerasan fisik dan psikis anak. Menurut laporan Kementrian Sosial yang disampaikan oleh Nahar, Direktur Rehabilitasi Sosial Anak, hingga tahun 2017 tercatat 400 kasus kekerasan seksual dan 117 kasus bullying terjadi di Indonesia. (www.cnnindonesia.com). Dinas Pemberdayaan Perempuan dan Perlindungan Anak (DP3A) Kabupaten Bekasi, dalam hal ini diwakili oleh Kepala DP3A, Sutiaresmulyawan, melaporkan bahwa pada bulan Januari hingga Maret 2017 telah terjadi 17 kasus kekerasan seksual pada anak dan perempuan. Kejadian ini menimbulkan trauma sehingga anak tersebut membutuhkan pendampingan psikologis. (https://beritacikarang.com/tiga-bulan-17-kasus-kekerasan-terhadapperempuan-dan-anak-terjadi-di-kabupaten-bekasi).

Pada bulan September 2019 yang lalu, kembali terjadi kasus bullying yang mengakibatkan korbannya meninggal dunia. (https://www.suara.com/news/2019/09/09/165603/bocah-korbanbullying-di-bekasi-meninggal-sempat-merintih-ucap-nama-pelaku)

Perilaku bullying saat ini tidak hanya dilakukan oleh kaum dewasa tetapi juga telah merambah ke golongan remaja. Masa remaja adalah masa perkembangan manusia yang ditandai dengan adanya perubahan fisik, kognitif, sosial dan psikologis (Desmita, 2010 dalam Mulachela \& Prasetyaningrum, 2017). Perubahan fisik, kognitif, sosial dan psikologi yang tidak dapat dikuasai oleh sebagian remaja seringkali berdampak pada gejolak emosi yang bisa menimbulkan konflik internal dan frustasi. Manifestasi dari rasa frustasi tersebut dapat diluapkan dalam bentuk tindakan kekerasan untuk menyakiti diri sendiri dan orang lain (Baron \& Byrne, 2012; Mulachela \& Prasetyaningrum, 2017). Masa remaja juga ditandai dengan adanya kebutuhan remaja untuk mendapatkan pengakuan atas keberadaan mereka. Sebagian besar remaja melakukan tindakan bullying demi menunjukkan eksistensi dan egosentrik mereka tanpa mereka memahami dampak dari tindakan tersebut (Shidiqi \& Suprapti, 2013; Mulachela \& Prasetyaningrum, 2017).

Tindakan bullying ini bila tidak diselesaikan dengan baik akan berdampak jangka panjang bagi perkembangan fisik dan psikologis anak. Masalah yang mungkin muncul sebagai dampak bullying diantaranya depresi, kegelisahan, rasa tidak aman di sekolah, penurunan minat belajar dan prestasi akademik (Zakiyah, et.al, 2017). Menurut penelitian Septriana et.al (2009) perilaku bullying juga memiliki hubungan dengan self-esteem. Dampak panjang dari emosi negative yang didapatkan oleh korban bullying dapat berupa perasaan rendah diri (low self-esteem). Self-esteem adalah penilaian yang membuat seseorang menghargai dirinya (Papalia, 2002 dalam Septriana, et.al, 2009). Self-esteem mempengaruhi perilaku seseorang, membuat ia merasa berarti, menghargai dirinya, percaya diri memiliki self-security dan akhirnya bertanggung jawab pada segala hal yang ia lakukan (Horrocks\&Jackson, 1972 dalam Prihadi \& Chua, 2012) Beranjak dari fenomena ini, peneliti mencoba untuk melakukan sosialisasi kepada kaum remaja mengenai dampak bullying serta cara meningkatkan self-esteem.

Berdasarkan latar belakang masalah di atas, maka rumusan masalah dalam kegiatan pengabdian kepada masyarakat ini adalah :

1. Bagaimana cara mensosialisasikan pengertian dan dampak bullying kepada remaja? 
2. Bagaimana cara meningkatkan self esteem pada remaja?

Tujuan dari pelaksanaan kegiatan Pengabdian Kepada Masyarakat ini adalah :

1. Memberikan psikoedukasi kepada remaja mengenai pengertian serta dampak bullying.

2. Memberikan pemahaman kepada remaja untuk mulai menghargai perbedaan, memandang positive orang lain dan saling mengasihi.

3. Memberikan pemahaman kepada remaja mengenai pentingnya meningkatkan self esteem bagi masa depan mereka.

\section{LANDASAN TEORI}

\section{Remaja}

Ada beberapa teori mengenai masa remaja menurut para ahli seperti Hurlock, Santrock serta World Health Organization (WHO) yang seringkali dikutip dalam berbagai penelitian. Masa remaja didefinisikan sebagai masa transisi dari masa kanak - kanak ke masa dewasa yang ditandai dengan adanya perkembangan biologis, kognitif, serta social emosional. Masa remaja berada dalam rentang usia 12 - 22 tahun. (Pigozi \& Machado, 2015; Mulachela \& Prasetyaningrum, 2017)

Dalam periode ini, mereka mencoba mencari jati diri atau identitas, mempelajari ilmu serta ketrampilan baru, belajar untuk mengontrol emosi dan relasi sosial mereka. Pada masa ini remaja membutuhkan pengakuan Kesehatan perkembangan secara kognitif, emosional, seksual dan psikologis selama masa remaja sangat ditunjang oleh adanya lingkungan yang aman, memberikan dukungan serta proteksi bagi para remaja. (Spano, 2004; Pigozi \& Machado, 2015; Mulachela \& Prasetyaningrum, 2017)

\section{Bullying}

Bullying dapat diartikan sebagai tindakan menyakiti orang lain secara verbal, fisik, maupun psikologis untuk menunjukkan kekuasaannya sehingga menyebabkan timbulnya trauma, dan perasaan tertekan dari korbannya. Tidak hanya mempengaruhi dalam jangka waktu pendek, bullying juga dapat mempengaruhi seseorang dalam jangka panjang seperti dalam hal hasil belajar, kesehatan fisik dan mental, psychological wellbeing, perasaan rendah diri, tidak berdaya hingga kasus bunuh diri. (Septrina, dkk, 2009; Australia's Safe, 2015; Zakiyah, dkk, 2017;).

Ada beberapa bentuk bullying (Al-Raqqad, dkk, 2017) yaitu :

a. Physical bullying

Meliputi pemukulan, menampar, menendang atau memaksa untuk melakukan sesuatu.

b. Verbal bullying

Meliputi penyalahgunaan secara verbal, penghinaan, mengutuk, ancaman, pemberian nama sebagai ejekan, labelling berdasarkan etnis tertentu.

c. Sexual bullying

Meliputi penggunaan kata - kata kotor serta pelecehan seksual

d. Psychological bullying

Meliputi tindakan penolakan, intimidasi, ancaman.

e. Bullying dalam relasi social

Seperti menolak seseorang bergabung dalam kelompok atau menyebarkan gossip tidak benar tentang orang lain dalam kelompok social.

f. Properties bullying

Seperti mengambil, membuang atau merusak barang milik orang lain. 


\section{Self-esteem}

Self esteem dapat diartikan sebagai penilaian seseorang terhadap dirinya sendiri baik positif maupun negative. Self esteem yang tinggi ditandai dengan sikap menghargai dan memandang diri sendiri secara positive. (Septrina, 2009; Awlawi, 2013; Cash \& Burke, 2014; Hidayati, 2014) Ada 3 aspek self-esteem yaitu :

a. Perasaan terhadap diri sendiri

Merupakan kemampuan individu untuk menghormati, menerima kelebihan serta kekurangan diri sendiri.

b. Perasaan tentang hidup

Tanggung jawab atas hidup yang dijalani, menerima kenyataan dan tidak menyalahkan orang lain atas apa yang terjadi dalam hidupnya.

c. Hubungan dengan orang lain.

Kemampuan untuk menghargai orang lain, menyadari bahwa setiap orang memiliki hak yang sama.

\section{METODE PELAKSANAAN}

Kurangnya pemahaman akan dampak bullying menyebabkan remaja melakukan tindak bullying. Pengajaran tentang bullying serta dampaknya bagi perkembangan fisik dan psikologis diharapkan dapat membantu remaja untuk mengurangi tindak bullying dalam pergaulan mereka.

Penelitian ini menggunakan metode deskriptif kualitatif di mana peneliti mendeskripsikan data yang di dapat di lapangan secara sistematis kemudian menganalisa dengan cara membandingkan data dengan standar normative yang ada. Tujuan penelitian ini adalah memberikan gambaran secara sistematis, aktual dan akurat mengenai fenomena yang diteliti. Peneliti mengumpulkan data dari para remaja di beberapa Sekolah Menengah Atas (SMA), Sekolah Menengah Kejuruan (SMK) ataupun perkumpulan keagamaan kaum remaja dengan cara wawancara, diskusi serta observasi.

\section{Waktu dan Lokasi}

Psikoedukasi mengenai dampak bullying dan cara meningkatkan self-esteem di kalangan remaja ini dilakukan di beberapa Sekolah Menengah Atas, Sekolah Menengah Kejuruan maupun perkumpulan keagamaan kaum remaja di wilayah Cikarang - Bekasi. Kegiatan ini berlangsung sejak bulan September hingga Desember 2019.

\section{Prosedur}

Psikoedukasi adalah salah satu metode yang akan diadakan untuk mengajarkan remaja tentang bullying dan dampaknya. Metode yang akan digunakan adalah survey lapangan, ceramah, diskusi kelompok, konseling, role play, permainan, pembuatan rencana tindakan perubahan. Tahapan psikoedukasi yang dilakukan adalah :

a. Pelatihan tentang keberagaman (diversity) serta cara menghargai orang lain

Melalui pelatihan ini, peneliti mengingatkan kembali tentang makna Bhineka Tunggal Ika kepada para remaja. Kegiatan yang ditujukan untuk membuat para remaja mengenal sisi positif, merasa saling membutuhkan dan menghargai teman - temannya dilakukan melalui role play, permainan dan diskusi.

b. Pelatihan mengenai bullying dan dampaknya

Pengenalan mengenai pengertian, dampak bullying jangka pendek dan panjang disertai contoh - contoh kasus yang telah terjadi dilakukan melalui ceramah dan diskusi beberapa kasus yang terjadi. Melalui paparan kasus dampak bullying, peneliti mengajak para remaja ini untuk mengerti resiko jangka panjang dari tindakan - tindakan yang terkadang dianggap biasa oleh mereka. 
c. Pelatihan untuk meningkatkan self-esteem

Sesi pelatihan selanjutnya dilakukan agar mereka dapat melihat sisi positif dari diri mereka dan menghargai keberadaan orang lain. Peneliti meminta para remaja untuk membuat jurnal pribadi mengenai hal positif yang ada dalam diri mereka, mencatat keberhasilan atau berkat yang mereka dapatkan atau telah bagikan kepada orang setiap harinya. Melalui jurnal pribadi ini diharapkan dapat meningkatkan rasa bersyukur, percaya diri dan keberhargaan para remaja di tengah masa transisi mereka.

\section{HASIL DAN PEMBAHASAN}

Sebelum memulai program psikoedukasi, peneliti melakukan wawancara, diskusi serta observasi awal dengan beberapa remaja di wilayah sekitar Cikarang - Bekasi. Hasil observasi dan diskusi awal mendapatkan bahwa banyak remaja belum menyadari tentang jenis bullying serta dampaknya. Mereka terbiasa untuk melakukan labeling kepada teman - temannya seperti memanggil temannya dengan sebutan "hitam", "gendut", atau panggilan lain yang sebenarnya menghina namun dianggap lelucon oleh mereka. Kurangnya pemahaman para remaja ini terhadap pengertian dan jenis bullying membuat mereka melakukan hal ini setiap hari tanpa rasa bersalah, mengikuti kebiasaan yang ada di lingkungan sekitar mereka.

Hasil pengamatan dan wawancara juga mendapatkan bahwa sejauh ini tidak banyak anak - anak korban bullying yang berani melaporkan tindakan bullying yang mereka alami kepada guru atau orang tua. Kebanyakan dari mereka hanya memendam rasa sedih yang mereka rasakan di dalam hati. Sebagian dari remaja korban bullying ini akhirnya lebih memilih untuk diam, menganggap diri mereka rendah, minder, menghindari relasi sosial atau ada pula yang justru belajar serta mempraktekan perilaku bullying.

\section{Hasil sesudah sosialisasi}

Melalui program psikoedukasi yang dilakukan, ada beberapa hasil yang didapatkan, diantaranya :

a. Remaja mulai memahami pengertian, jenis dan dampak bullying

Dalam sesi ceramah dan diskusi, beberapa remaja baru mengetahui bahwa tindakan yang selama ini mereka lakukan kepada teman mereka tergolong bullying seperti yang dapat dilihat pada Gambar 1. Melalui sesi sharing, peneliti mencoba menanyakan apa yang dirasakan serta dipikirkan oleh pelaku dan korban bullying. Ketika mereka mencoba menceritakan secara terbuka kemudian mendengarkan dan memahami dampak yang dialami, mereka akhirnya dapat menarik kesimpulan dan pembelajaran secara pribadi. Mereka belajar mengenai dampak jangka panjang yang akan terjadi. Peneliti juga mengajak mereka untuk memposisikan diri mereka sebagai korban agar mereka dapat lebih memahami efek yang kemungkinan didapatkan.

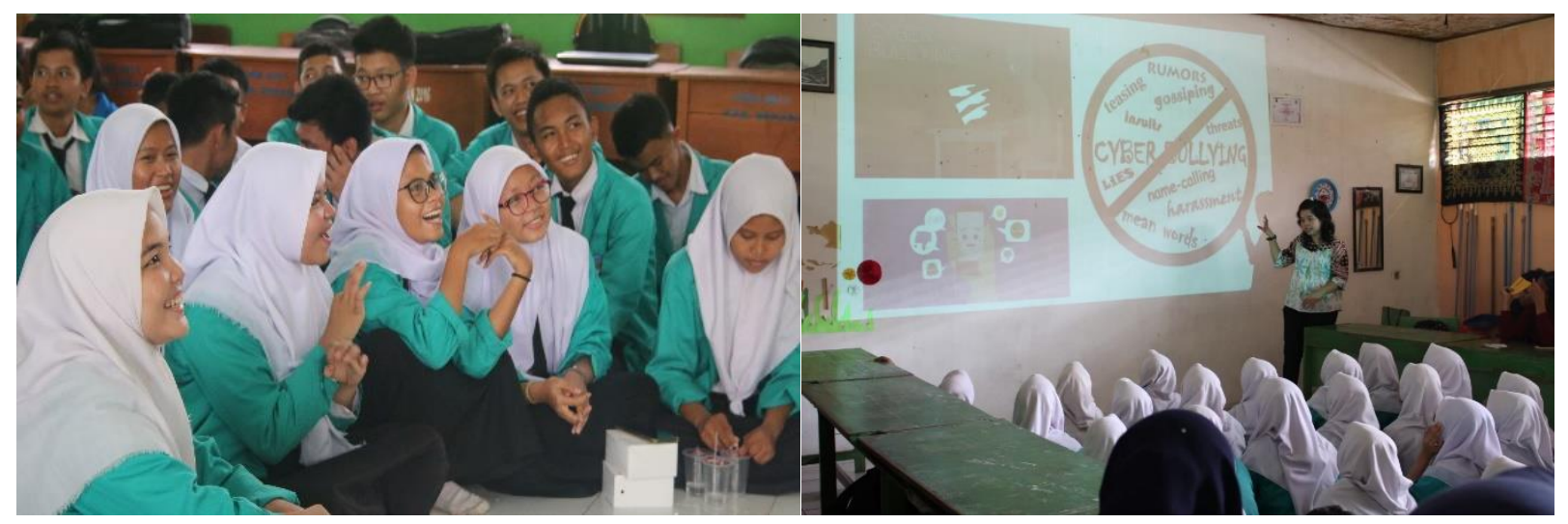

Gambar 1. Sesi Ceramah dan Diskusi 
b. Para peserta psikoedukasi mulai mengingat kembali arti Bhineka Tunggal Ika dan berusaha untuk menunjukkan rasa saling mengasihi dan menghargai. Melalui role play dan permainan tentang keberagaman dan pentingnya sikap Bhineka Tunggal Ika, para peserta mencoba untuk melihat nilai positif dari teman - temannya seperti yang dapat dilihat pada Gambar 2. Mereka juga belajar bahwa sebagai mahluk social mereka saling membutuhkan dan melengkapi. Tidak ada satu orangpun yang sempurna sehingga mereka harus belajar untuk melihat hal positif dari orang lain dan saling menghargai.

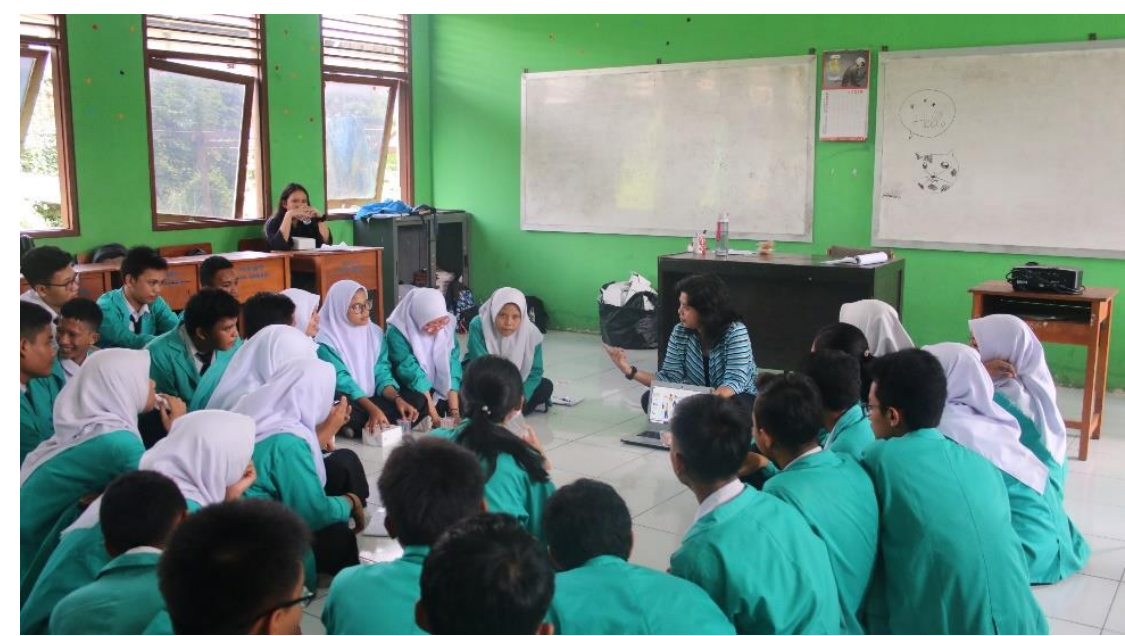

Gambar 2. Sesi Role Play dan Permainan tentang Keberagaman dan pentingnya sikap Bhineka Tunggal Ika

c. Remaja - remaja ini mencoba untuk meningkatkan rasa bangga mereka kepada diri sendiri Dari hasil diskusi, ceramah dan role play beberapa orang remaja menyadari bahwa dampak jangka pendek bullying telah mereka rasakan seperti adanya rasa rendah diri. Mereka merasa dirinya tidak berharga sehingga mereka kurang berani untuk mencoba sesuatu yang baru atau mengeksplorasi kemampuan mereka. Mereka acapkali membandingkan diri mereka dengan orang lain yang dianggap berhasil oleh standar di lingkungan sekitar mereka, misalnya remaja pria dikatakan keren bila dapat bermain basket sehingga ketika mereka tidak dapat bermain basket, mereka merasa diri mereka bukanlah seseorang yang sempurna.

Melalui kegiatan untuk menceritakan serta mencatat setiap hal positif dan berharga yang mereka dapatkan setiap hari dalam jurnal harian, mereka kembali mengingat bahwa mereka adalah mahluk ciptaan Tuhan yang sempurna. Pada awalnya mereka sedikit mengalami kesulitan untuk mengingat prestasi, keberhasilan atau hal positif yang mereka miliki karena mereka lebih banyak berpikir negative terhadap diri mereka sendiri. Ketika peneliti mencoba mengingatkan hal kecil yang seringkali terlupakan namun merupakan hal positif yang perlu dibanggakan, misalnya dapat bernafas tanpa alat bantu, memiliki tubuh yang sempurna dan punya kesempatan untuk sekolah, mereka baru menyadari bahwa sebenarnya banyak hal positif yang mereka bisa banggakan.

Pada akhir sesi, peneliti meminta mereka untuk terus melakukan hal ini secara rutin agar mereka dapat meningkatkan self esteem dan mempertahankan high self esteem hingga masa depan seperti yang dapat dilihat pada Gambar 3. 


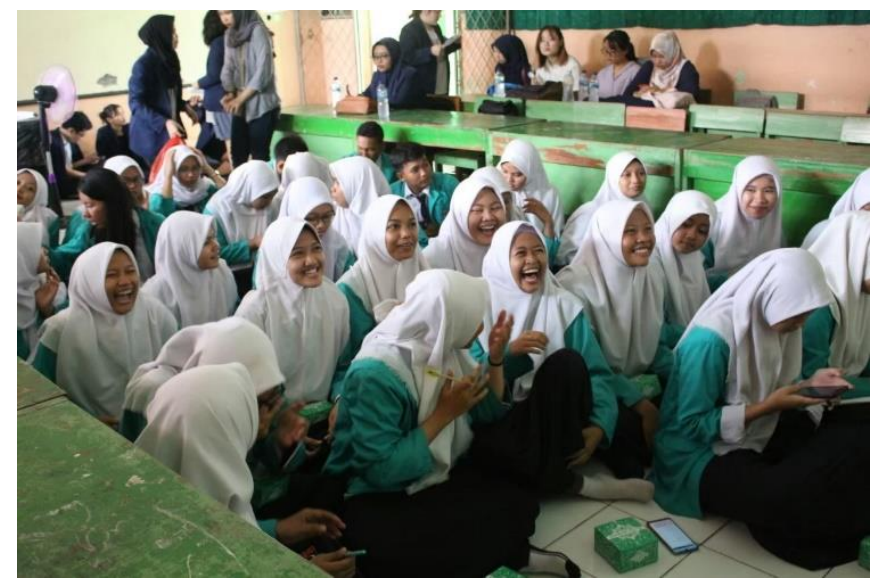

Gambar 3. Sesi Akhir

\section{KESIMPULAN DAN SARAN}

Syukur kepada Tuhan karena akhirnya kegiatan psikoedukasi dampak bullying dan cara meningkatkan self esteem pada remaja dapat berjalan dengan lancar. Melalui kegiatan ini dapat disimpulkan bahwa :

1. Melalui psikoedukasi ini, para remaja memahami pengertian, jenis serta dampak bullying baik jangka pendek maupun jangka panjang sehingga mereka berjanji untuk bersikap menolak bullying mulai dari diri mereka sendiri.

2. Para remaja belajar bahwa manusia adalah mahluk social yang saling membutuhkan. Mereka belajar tentang makna keberagaman dan Bhineka Tunggal Ika serta berusaha mengimplementasikannya dalam kehidupan mereka selanjutnya dengan cara menghargai perbedaan yang ada di lingkungannya.

3. Remaja - remaja ini belajar untuk lebih menghargai diri mereka, melihat hal positif yang telah diberikan Tuhan kepada mereka. Mereka mencoba untuk selalu menanamkan dalam diri mereka bahwa mereka adalah mahluk yang sempurna dan berharga di mata Tuhan sehingga walaupun lingkungan di sekitar mereka mungkin tidak menghargai, mereka tetap dapat melihat hal positif dalam diri mereka.

\section{Saran}

Pelaksanaan PKM ini masih belum sempurna sehingga masih perlu dilakukan beberapa perbaikan dan peningkatan seperti :

1. Melaksanakan kegiatan serupa di tempat - tempat lain sehingga banyak remaja yang dapat menunjukkan sikap menolak bullying

2. Melakukan kegiatan serupa tidak hanya di lingkungan remaja tetapi dapat pula mulai diterapkan dari usia dini karena saat ini kasus bullying tidak hanya terjadi dalam masa remaja tetapi juga telah merambah ke usia Sekolah Dasar.

\section{REFERENSI}

Al-Raqqad, et.al, 2017, The Impact of School Bullying on Student's Academic Achievement from Teacher Point of View. International Education Studies Journal. Vol 10 (6)

Mulachela \& Prasetyaningrum, 2017, Perilaku Bullying pada Remaja ditinjau dari Self-esteem dan jenis kelamin
Morelli.
Adolescent
Cognitive
Development.

https://www.risas.org/poc/view_doc.php?type=doc\&id=41156\&cn=1310

Pigozi. Pamela L \& Machado. 2015. Bullying during adolescence in Brazil: an overview. Ciencia \&Saude Colective. Vol 20(11):3509 - 3522 
Prihadi K, Chua M. (2012). Students' Self-Esteem at School: The Risk, the Challenge, and the Cure. Journal of Education and Learning. Vol.6 (1) pp. 1-14.

Rattew.D \& Pawlowski. S, 2015. Bullying. Journal of Child and Adolescent Psychiatric Clinics of North America. Vol $25 \quad$ (2),April 2016, pp $235 \quad$ - 242, https://doi.org/10.1016/j.chc.2015.12.002

Septrina, M.A., et.al, 2009. Hubungan Tindakan Bullying di Sekolah dengan Self-Esteem Siswa, Proceeding PESAT (Psikologi, Ekonomi, Sastra, Arsitektur\&Sipil) Universitas Gunadarma, vol 3, Oktober 2009

Shidiqi,M.F.,\& Suprapti,V. (2013).Pemaknaan Bullying pada Remaja Penindas (The Bully). Journal Psikologi Kepribadian dan Sosial, Vol 2(2), 90 - 98

Spano. 2004. Stages of Adolescent Development http://www.actforyouth.net/resources/rf/rf_stages_0504.pdf

Zakiyah, Ela, et.al, 2017, Faktor yang mempengaruhi remaja dalam melakukan bullying, Journal Penelitian \& PPM, Vol 4 no 2, Juli 2017

https://www.cnnindonesia.com/gaya-hidup/20170722163858-277-229641/semakin-banyakyang-melaporkan-kasus-bullying

https://beritacikarang.com/tiga-bulan-17-kasus-kekerasan-terhadap-perempuan-dan-anak-terjadidi-kabupaten-bekasi/

https://www.suara.com/news/2019/09/09/165603/bocah-korban-bullying-di-bekasi-meninggalsempat-merintih-ucap-nama-pelaku

https://bullyingnoway.gov.au/UnderstandingBullying 